\title{
A abordagem midiática sobre o esporte paralímpico: 0 ponto de vista de atletas brasileiros
}

\author{
Renato Francisco Rodrigues Marques* \\ Gustavo Luis Gutierrez** \\ Marco Antonio Bettine de Almeida*** \\ Myrian Nunomura**** \\ Rafael Pombo Menezes*****
}

\begin{abstract}
Resumo: O esporte paralímpico encontra-se em processo de afirmação social e econômica e tem na mídia a principal ferramenta de divulgação de seus ideais e produtos. Baseado em conceitos da teoria dos campos de Pierre Bourdieu, o objetivo deste trabalho foi investigar o ponto de vista de atletas brasileiros sobre conteúdos, meios e abrangência da divulgação midiática sobre o esporte paralímpico, de modo a propor reflexões sobre suas expectativas e percepções. A partir de entrevistas semiestruturadas com 23 atletas paralímpicos brasileiros e análise de discurso baseada no método Discurso do Sujeito Coletivo, tem-se como principais resultados: a divulgação paralímpica é pequena, porém está em crescimento; os atletas dividem sua preferência entre a divulgação de feitos esportivos e a ideia de superação da deficiência.
\end{abstract}

Palavras-chave: Esportes. Mídia audiovisual. Pessoas com deficiência. Sociologia.

\footnotetext{
'Escola de Educação Física e Esporte de Ribeirão Preto. Universidade de São Paulo. Ribeirão Preto, SP, Brasil. E-mail: renatomarques@usp.br

"Faculdade de Educação Física. Universidade Estadual de Campinas. Campinas, SP. Brasil. E-mail: gutierrez@fef.unicamp.br

"*"Escola de Artes Ciências e Humanidades. Universidade de São Paulo. São Paulo, SP, Brasil. E-mail: marcobettine@usp.br

"*t* Escola de Educação Física e Esporte de Ribeirão Preto. Universidade de São Paulo. Ribeirão Preto, SP, Brasil. E-mail: mnunomur@usp.br

Escola de Educação Física e Esporte de Ribeirão Preto. Universidade de São Paulo. Ribeirão Preto, SP, Brasil. E-mail: rafaelpombo@usp.br
} 


\section{INTRODUÇão}

O esporte paralímpico teve sua origem em finalidades terapêuticas e recreativas, porém, no século XXI, apresenta características próprias do alto rendimento (BAILEY, 2008). Desde o final da década de 1990, essa forma de manifestação esportiva passa por um processo de afirmação como prática espetacularizada e de crescimento de sua comercialização (MARQUES et al., 2009). Tal fenômeno tem produzido certa transformação social em relação à participação e reconhecimento de pessoas com deficiência em posições de destaque na sociedade (BRITTAIN, 2010).

Existe uma interdependência entre mídia, exposição e acúmulo financeiro no esporte-espetáculo. Nessa relação, os meios de comunicação precisam do esporte como conteúdo a ser comercializado e o esporte precisa ser divulgado de modo a gerar lucros (COAKLEY, 2008).

O interesse comercial no esporte se pauta por sua proximidade com espectadores, que se tornam consumidores, e o desejo das empresas de se aproximarem dessas pessoas para vender seus produtos (HOWE, 2004). Os meios de comunicação colocam-se como ferramentas indispensáveis nesse processo, como forma de disseminação de ideias e ideais e promoção de produtos. Talvez o aspecto econômico seja o mais significativo no envolvimento entre mídia e esporte (HOWE, 2008). Nesse cenário, a divulgação midiática do esporte paralímpico é uma forma de expandir ideais inclusivos, esportivos e comerciais, e o coloca em um mercado altamente competitivo, no qual disputa espaço com outras formas de manifestações esportivas (PURDUE; HOWE, 2012).

Considerando esse panorama, a problemática desta pesquisa pautou-se em desvelar a opinião de atletas paralímpicos brasileiros a respeito da abordagem midiática sobre o movimento paralímpico e algumas implicações sobre suas possibilidades de atuação em alguns espaços sociais, principalmente no campo esportivo e em relação à discussão sobre inclusão social. Tal investigação 
justifica-se pela disponibilização da perspectiva de protagonistas do movimento paralímpico sobre a forma com que seu campo de atuação é apresentado e oferecido ao grande público. Essas informações podem contribuir, entre outras possibilidades, para reflexões sobre promoção de inclusão social e desenvolvimento do esporte de alto rendimento.

Com base em categorias próprias da teoria dos campos de Pierre Bourdieu, o objetivo deste trabalho foi investigar o ponto de vista de atletas paralímpicos brasileiros sobre conteúdos, meios e abrangência da divulgação midiática sobre o esporte paralímpico, de modo a propor reflexões sobre suas expectativas e percepções.

\section{Decisões metodológicas}

Esta foi uma pesquisa qualitativa, com coleta de dados baseada em entrevistas pessoais e semiestruturadas com atletas paralímpicos brasileiros, realizadas em locais indicados pelos sujeitos (centros de treinamento, hotéis, instituições de atendimento a pessoas com deficiência, residências), em ambientes fechados, com o cuidado de garantir o silêncio e evitar interrupções, e em horários diferentes dos momentos de treinos e competições.

Foram considerados atletas paralímpicos indivíduos que treinam e competem, de forma sistemática e oficial, uma das modalidades dos programas dos Jogos Paralímpicos (JP), organizados pelo Comitê Paralímpico Internacional. Tal determinação baseia-se na definição proposta por Costa e Winckler (2012), na qual o esporte paralímpico caracteriza-se por um ambiente restrito, que envolve as modalidades dos JP e é acessível apenas a pessoas que se enquadrem nos critérios de classificação, sendo elegíveis para as disputas.

O número final de sujeitos foi determinado pelo critério de saturação (MINAYO, 2006). Foram entrevistados 23 atletas paralímpicos brasileiros adultos, participantes de diversas modalidades esportivas, com deficiência visual ou física, de ambos

Movimento, Porto Alegre, v. 20, n. 3, p. 989-1015, jul./set. de 2014. 
os sexos e diferentes níveis de competição. Os sujeitos foram denominados aleatoriamente como S1 a S23, de modo a preservar suas identidades. O Quadro 1 apresenta os atletas selecionados, com cinco de suas características:

Quadro 1: Características dos atletas entrevistados.

\begin{tabular}{|c|c|c|c|c|c|}
\hline Sujeito & Sexo & Modalidade & Deficiência & $\begin{array}{c}\text { Nível de } \\
\text { competição }\end{array}$ & $\begin{array}{c}\text { Seleção } \\
\text { Nacional }\end{array}$ \\
\hline $\mathrm{S} 1$ & $\mathrm{~F}$ & Natação & DV & Nacional & Não \\
\hline $\mathrm{S} 2$ & $\mathrm{~F}$ & Goalball & DV & Regional & Não \\
\hline S3 & $\mathrm{F}$ & Goalball & DV & Regional & Não \\
\hline $\mathrm{S} 4$ & $\mathrm{~F}$ & Goalball & DV & Internacional & Sim \\
\hline S5 & M & Goalball & DV & Internacional & Sim \\
\hline S6 & M & Atletismo & DF & Jogos Paralímpicos & Sim \\
\hline S7 & $\mathrm{F}$ & Atletismo & DV & Jogos Paralímpicos & Sim \\
\hline S8 & $\mathrm{F}$ & Atletismo & DF & Jogos Paralímpicos & Sim \\
\hline S9 & M & Natação & DF & Jogos Paralímpicos & Sim \\
\hline $\mathrm{S} 10$ & M & Natação & DF & Jogos Paralímpicos & Sim \\
\hline S11 & M & Rugby & DF & Internacional & Sim \\
\hline S12 & M & Rugby & DF & Internacional & Sim \\
\hline $\mathrm{S} 13$ & M & Rugby & DF & Internacional & Sim \\
\hline S14 & M & Basquetebol & DF & Regional & Não \\
\hline $\mathrm{S} 15$ & M & Basquetebol & DF & Regional & Não \\
\hline S16 & M & Basquetebol & DF & Regional & Não \\
\hline S17 & $\mathrm{F}$ & Basquetebol & DF & Regional & Não \\
\hline S18 & M & Basquetebol & DF & Regional & Não \\
\hline S19 & M & Goalball & DV & Jogos Paralímpicos & Sim \\
\hline $\mathrm{S} 20$ & M & Goalball & DV & Jogos Paralímpicos & Sim \\
\hline $\mathrm{S} 21$ & M & Goalball & DV & Jogos Paralímpicos & Sim \\
\hline $\mathrm{S} 22$ & M & Goalball & DV & Jogos Paralímpicos & Sim \\
\hline $\mathrm{S} 23$ & M & Goalball & DV & Jogos Paralímpicos & Sim \\
\hline
\end{tabular}

Legenda: F - Feminino; M - Masculino; DV - Deficiência Visual; DF - Deficiência Física; Seleção Nacional - Sim: atletas que fazem ou já fizeram parte do quadro da seleção brasileira da modalidade praticada; Não: atletas que nunca fizeram parte de tal quadro. Fonte: dados originais da pesquisa 
Após a transcrição dos áudios das entrevistas, a análise dos discursos se deu pela utilização do método -"Discurso do Sujeito Coletivo"-. Esta proposta de pesquisa baseia-se no conceito de Representação Social, que, dentro do plano simbólico de trocas entre diferentes agentes sociais em um campo, permite a comunicação e compreensão de diferentes sentidos, proporcionando coesão entre os membros de um mesmo espaço social. Nesse cenário, o objetivo deste método consiste em delimitar conteúdos de ordem coletiva, ou seja, que representem a opinião e posicionamento político-social de grupos de sujeitos, sem eliminar as diferentes opiniões que podem surgir dentro de um mesmo campo, também consideradas na análise de resultados (LEFÈVRE; LEFÈVRE, 2012).

O produto dessa forma de pesquisa consiste na construção de diferentes Discursos do Sujeito Coletivo (DSC), que englobem posicionamentos comuns entre os entrevistados (LEFÈVRE; LEFÈVRE, 2005). Essa forma de análise baseia-se na premissa de que, em um mesmo grupo, existem diferentes tipos ou categorias de pensamento coletivo, e que a construção de diferentes DSC sintetiza e simboliza tal diversidade (LEFÈVRE; LEFÈVRE, 2012), própria de contextos de turbulências sociais, que envolvem trocas simbólicas e disputas por poder e reconhecimento social (BOURDIEU, 1983, 1989, 1990, 2003).

Embora seja baseada na busca por consensos sobre diversos temas, também são esperados dissensos e, consequentemente, discursos com pequena intensidade ou força (poucos sujeitos que compartilham de determinada opinião) (LEFÈVRE; LEFÈVRE, 2012).

A organização dos dados com base nesse método se dá a partir de figuras metodológicas que, encadeadas e relacionadas, ordenam as informações: Expressões-chave (ECH) - trechos/ partes literais do discurso que sugerem aproximações à essência do mesmo; Ideias Centrais (IC) - tema central do discurso, indica pontos e categorias que podem contribuir na discussão do tema (LEFÈVRE; LEFÈVRE, 2005).

Movimento, Porto Alegre, v. 20, n. 3, p. 989-1015, jul./set. de 2014. 
O DSC se baseia em um discurso-síntese redigido pelo pesquisador e composto pela soma das ECH de cada discurso individual que possui as mesmas IC. Para a elaboração dos DSC, as ECH foram destacadas e transportadas para Instrumentos de Análise do Discurso, no qual foram apontadas as IC. Com base em análise das $\mathrm{IC}$, as ECH foram agrupadas de acordo com sentidos homogêneos, construindo DSC diferentes (LEFÈVRE; LEFÈVRE, 2005).

Esta pesquisa foi submetida e aprovada pela Comissão Científica da Academia Paralímpica Brasileira, que auxiliou no contato com os atletas e concedeu autorização para acesso aos locais de execução, e pelo Comitê de Ética em Pesquisa da Faculdade de Filosofia Ciências e Letras de Ribeirão Preto - Universidade de São Paulo. Todos os sujeitos assinaram o termo de consentimento livre e esclarecido.

Foram realizadas duas perguntas iniciais:

1) Como você classificaria a atenção dada pela mídia ao esporte paralímpico?

2) Como é a relação dos atletas paralímpicos com a mídia?

De acordo com os temas oriundos das conversas, novas questões surgiram. Isso explica o fato de nem todos os atletas terem manifestado opinião sobre todos os temas expostos na seção de análise e discussão. Tal ocorrência, somada aos dissensos próprios dos campos sociais, produziu três DSC com apenas um sujeito como "orador" (Tema 1 - DSC-4 e DSC-7; Tema 3 - DSC-2). O que, nesses casos específicos, caracteriza, segundo Massa, Uezu e Böhme (2010), discursos legítimos de análise, mas que não se configuram como formas essencialmente coletivas.

\section{ANÁLISE E DISCUSSÃo}

Nesta seção são descritos os discursos-síntese, provenientes da análise dos discursos dos entrevistados, expressos pela descrição

Movimento, Porto Alegre, v. 20, n. 3, p. 989-1015, jul./set. de 2014. 
das IC e DSC, seguidos da discussão dos dados, divididos de acordo com temas oriundos das entrevistas. Juntamente aos títulos das IC, são apontados os sujeitos que compartilham de tal posicionamento, de modo a demonstrar a intensidade/força dos discursos dentro da amostra de sujeitos entrevistada.

Tema 1: Divulgação do esporte paralímpico na mídia.

DSC1 - IC-A: Não há uma divulgação satisfatória. Por isso, o público conhece pouco sobre esporte paralímpico - S2; S3; S8; S12; S13; S17; S18; S20; S21; S22; S23

É muito pequeno o espaço que a mídia dá para o esporte paralímpico. É raro aparecer algo na TV. Acho que poderia divulgar um pouquinho mais, pois a imprensa às vezes não cobre porque acha que isso não vai dar retorno, porque ninguém vai assistir, e as pessoas não se interessam e não assistem porque a imprensa não divulga.

DSC2 - IC-B: Divulgação do esporte paralímpico é temporária e restrita a grandes eventos - S2; S8; S9; S13; S19; S20; S22

A divulgação melhorou só porque vai ter a paralimpíada no Brasil. A gente tentou divulgar o Grand Prix de Goalball lá no Nordeste, deixou nota para o pessoal no rádio e na $\mathrm{TV}$, e dificilmente alguém divulgou alguma coisa. Não apareceu nenhuma emissora de TV para fazer a cobertura. A imprensa não dá nenhum incentivo durante o ciclo paralímpico, você aparece só naquele momento que conquistou alguma medalha nos Jogos, depois você é esquecido. Independente da situação do atleta, a mídia deveria acompanhar o dia a dia do esporte.

DSC3 - IC-C: Ocorre apenas divulgação dos melhores resultados - S2; S4; S6; S8; S19; S22

Eu fico um pouco chateado porque eles procuram o atleta só quando ganha medalha. Quando você vai para uma competição e consegue um resultado legal a mídia dá atenção. Eu acho que para a mídia o que importa são quantas medalhas você

Movimento, Porto Alegre, v. 20, n. 3, p. 989-1015, jul./set. de 2014. 
ganhou. Só no dia em que você ganha chegam os repórteres para te entrevistar, você é interessante pra eles só naquele momento. A mídia não deveria servir apenas para divulgar o resultado, mas sim, para cobrir uma competição nacional, regional, Grand Prix. Se a gente não tivesse conseguido uma medalha lá em Londres, a gente talvez não fosse nem citado na televisão.

DSC4 - IC-D: Modalidades exclusivamente paralímpicas têm maior dificuldade de divulgação do que as adaptadas, que o público já conhece - S21

O goalball, no caso, não é muito divulgado porque só cegos praticam. Já atletismo, natação, futebol, vôlei, todo mundo pratica. Todo mundo sabe o que é.

DSC5 - IC-E: A supremacia do futebol na mídia atrapalha S8; S13; S16; S21

$\mathrm{Eu}$ acho que a imprensa brasileira ainda se dedica muito a algumas modalidades específicas, principalmente ao futebol. Não só o paralímpico, mas outros esportes aqui no país também são prejudicados. A mídia hoje só fala em futebol.

\section{S7; S9; S10 \\ DSC6 - IC-F: A divulgação está crescendo - S1; S2; S4; S6;}

Aumentou. A gente não pode reclamar, porque tem melhorado muito. As pessoas têm procurado o esporte paralímpico. Antigamente parecia que não tinha muita importância. Hoje a cobertura midiática é espontânea. As pessoas buscam o esporte, não porque o nosso Comitê vai pagar um hotel bacana para o jornalista ou para qualquer emissora de TV fazer a cobertura da competição. Hoje a gente já sabe que a Paralimpíada vem na sequência da Olimpíada, e as pessoas também buscam por isso.

DSC7 - IC-G: A mídia brasileira tem dado maior destaque ao esporte paralímpico do que a internacional - S10

Movimento, Porto Alegre, v. 20, n. 3, p. 989-1015, jul./set. de 2014. 
Eu creio que aqui está um pouco melhor, por isso que eu digo que a gente está no caminho certo. A gente tem aparecido muito na mídia, e se começarmos a pensar, é muita coisa já para um esporte que, até 2004 , não tinha quase nada.

DSC8 - IC-H: Existe certa prioridade a modalidades individuais mais conhecidas, como a natação e o atletismo - S20; S21

Natação e atletismo são o carro-chefe das propagandas, dos patrocínios. Outras, como o goalball, conseguem certo espaço, mas não igual ao atletismo e à natação. Os esportes coletivos, de modo geral, ainda estão engatinhando em relação à divulgação na mídia.

Percebe-se que grande parte dos atletas mostra-se insatisfeita com a divulgação midiática do esporte paralímpico. Entretanto, como aponta a IC-F, alguns manifestam uma percepção otimista quanto à melhora desse quadro. As três primeiras IC sinalizam um descontentamento relativo à frequência da divulgação, além da denúncia de que, quando ela ocorre, é de modo superficial, com foco em grandes eventos ou apenas nos resultados positivos, não havendo uma cobertura ampla.

O posicionamento predominante de insatisfação com a divulgação do esporte paralímpico aponta para uma situação de desejo de maior reconhecimento como esportista e como sujeitos com potencial para atuação social de destaque. A ânsia por fazer do movimento paralímpico um fenômeno legitimado e consumido pelo grande público sinaliza uma busca por aquisição de um capital simbólico do campo esportivo contemporâneo, ligado, segundo Marques e Gutierrez (2009), ao reconhecimento do mérito esportivo e consequente possibilidade de ganhos financeiros e sociais.

Dois caminhos justificam a preocupação por maior destaque midiático: a) o reconhecimento das pessoas com deficiência (PCD) como membros produtivos da sociedade; b) a busca por melhores condições de treinamento e competição, pautada no reconhecimento

Movimento, Porto Alegre, v. 20, n. 3, p. 989-1015, jul./set. de 2014. 
desses sujeitos como atletas de alto rendimento e consequente aumento das possibilidades de ganhos sociais e financeiros. Tais perspectivas direcionam os discursos para uma maior valorização de uma perspectiva social sobre deficiência, que, segundo Munster et al. (2008), destaca a relação das PCD com a sociedade e sua potencialidade de relação com a mesma, em detrimento do modelo médico, que sobrevaloriza os impedimentos e limitações dos sujeitos e os responsabiliza por sua própria inserção nos espaços sociais.

Alguns autores corroboram o posicionamento dos entrevistados. Coakley (2008) afirma que atletas com deficiência recebem pouca ou nenhuma atenção da mídia. Pereira, Monteiro e Pereira (2011) destacam a predominância de matérias com ênfase nos resultados. Figueiredo e Novais (2011) apontam que as imprensas escritas brasileira e portuguesa, entre os JP de 1996 a 2008, seguiram na mesma direção de valorização dos resultados, em detrimento de outras temáticas sobre o evento, como questões organizacionais e, político-econômicas, expectativas dos atletas, bastidores ou doping.

A literatura sugere que existe uma lógica comercial que determina os conteúdos privilegiados no campo midiático, inclusive sobre o esporte paralímpico (SCHANTZ; GILBERT, 2001). Eles seriam escolhidos e elaborados com base na sua capacidade de gerar audiência (COAKLEY, 2008), por razões financeiras, interesse do público ou patrocinadores e "noticiabilidade" (BRITTAIN, 2004). Bourdieu (1997) aponta que a mídia, e principalmente a televisão, divulga o que lhe é interessante, seja do ponto de vista político ou econômico.

O esporte paralímpico é considerado um conteúdo de alto risco comercial para a mídia (COAKLEY, 2008). Uma das razões seria a dificuldade do grande público em relacioná-lo com o alto rendimento, devido a uma relação muito forte com a perspectiva da reabilitação e inclusão (PURDUE; HOWE, 2012). Neste sentido, são encontrados problemas para uma maior divulgação, 
principalmente oriundos da existência de uma perspectiva médica sobre deficiência ainda presente, tanto nos discursos dos agentes midiáticos, quanto no público em geral.

Existe certa resistência por parte de potenciais patrocinadores, frente à associação de sua marca a atletas com deficiência. Tal distanciamento deve-se principalmente: ao incômodo estético que afasta o atleta com deficiência de estereótipos de saúde e beleza; à falta de identificação entre o movimento paralímpico e o público consumidor; à dificuldade de associar uma imagem tida como frágil aos ideais esportivos de superioridade, força e vitórias (FARIA; CARVALHO, 2010).

$\mathrm{Na}$ contramão de tais tendências, alguns entrevistados relataram que, ainda assim, a divulgação midiática do esporte paralímpico tem melhorado nos últimos anos (IC-F e IC-G). Alguns autores corroboram essa percepção (BRITTAIN, 2004; HOWE, 2008; PEREIRA; MONTEIRO; PEREIRA, 2011). Para Figueiredo e Guerra (2005), os JP de 2004 simbolizam uma ruptura de transformação da relação entre a mídia e o esporte paralímpico. Os autores apontam que esse evento registrou uma audiência mundial de 1,8 bilhão de pessoas e representou, no Brasil, o início da perspectiva comercial sobre essa forma de esporte.

Outro ponto destacável do discurso dos entrevistados é a dificuldade do grande público conhecer e se aproximar do esporte paralímpico, causada principalmente por uma divulgação ainda insatisfatória (IC-A e IC-D) e pela concorrência com outras formas de manifestações esportivas (IC-E). Atletas norte-americanos apresentam discurso semelhante aos depoimentos de atletas brasileiros. Eles afirmam que o público pouco assiste às disputas porque pouco as conhece, devido à divulgação precária (BERGER, 2008).

Howe (2008) aponta que o grande público conhece pouco as particularidades do esporte paralímpico. Como exemplo, o sistema de classificação de atletas, que, segundo o autor, configura-se como o principal habitus do movimento paralímpico e que ainda

Movimento, Porto Alegre, v. 20, n. 3, p. 989-1015, jul./set. de 2014. 
se apresenta de forma confusa aos espectadores, devido à falta de divulgação e disseminação da cultura paralímpica por parte da mídia (HOWE, 2004).

Cria-se uma relação complexa em que o grande público não conhece o esporte paralímpico e por isso não o consome, ao passo que, por essa razão, os veículos de comunicação não o privilegiam devido ao risco de pequena audiência e retorno comercial insatisfatório.

O esporte tem desenvolvido, principalmente após o início da década de 1980, uma relação cada vez mais íntima com o capital econômico, pautada na comercialização de seus símbolos, produtos e diferentes formas de manifestação (MARQUES; GUTIERREZ; MONTAGNER, 2009). Tal perspectiva também exerce influência sobre o movimento paralímpico, que busca, através de maior espaço e reconhecimento midiático, ampliar suas possibilidades de inserção social e econômica. Nesse processo, o consumo do esporte paralímpico pelo público coloca-se como variável importante para o crescimento dessa forma de manifestação esportiva.

A mídia, por sua vez, coloca-se como ferramenta vital para a disseminação da cultura paralímpica. Nesse sentido, percebe-se a preocupação por parte dos atletas entrevistados em relação ao público melhor conhecer o esporte paralímpico e, consequentemente, embutir certa dose de responsabilidade sobre os veículos de comunicação em relação a essa situação insatisfatória. Seus discursos, em maioria, embora direcionados predominantemente à televisão, deixando em segundo plano outros veículos como jornais, revistas, internet, rádio, entre outros, apresentam-se carregados de descontentamento sobre a cobertura midiática.

Considerando que a mídia seja uma ferramenta importante para a disseminação da cultura esportiva (SILVA; HOWE, 2012), seria desejável que a lógica de divulgação do esporte paralímpico, e de outras manifestações esportivas pouco prestigiadas, fosse revista, de modo a atrair maior interesse do público. Tal movimento 
poderia acontecer em iniciativas conjuntas entre entidades organizadoras do esporte e os veículos de comunicação, como por exemplo, o financiamento, por parte do Comitê Paralímpico Brasileiro (CPB), a jornalistas do Brasil para cobrirem os JP de 2004 e 2008 (MARQUES, 2013).

Nesse sentido, a divulgação, não apenas dos resultados esportivos, mas também de notícias extracompetições, poderia contribuir para aproximar o grande público dos atletas e das diferentes modalidades paralímpicas (COAKLEY, 2008). Existe ainda, uma significativa falta de conhecimento sobre deficiência e esporte paralímpico por parte de jornalistas e agentes midiáticos (BRITTAIN, 2004), além da presença tímida de jornalistas com deficiência na cobertura dos eventos paralímpicos (HOWE, 2008).

Quanto à supremacia do futebol no espaço midiático (IC-E), Morato et al. (2011) ilustram esse quadro citando que jogadores brasileiros de futebol para cegos apontam como seus ídolos atletas de futebol e não da modalidade que eles próprios praticam. O que evidencia uma predominância, culturalmente estabelecida, do futebol sobre outras modalidades e certa secundarização da prática paralímpica mesmo dentro do campo esportivo.

Alguns atletas destacaram que existe certa prioridade, por parte da mídia, em divulgar algumas modalidades paralímpicas em detrimento de outras (IC-H). Percebe-se que ambos os sujeitos são atletas de modalidade coletiva (goalball) e denunciam o privilégio a modalidades individuais. Administradores do CPB apontam tal tendência no Brasil, onde as modalidades coletivas encontram maiores dificuldades para divulgação e obtenção de patrocínios, em relação às individuais (MARQUES; GUTIERREZ, 2014). Isso ocorreria devido à maior oferta de medalhas e à facilitada identificação dos atletas em comparação com as equipes.

Como último ponto do primeiro tema, tem-se a comparação entre a mídia brasileira e a internacional (IC-G). Alguns dados sustentam tal perspectiva de melhores condições no Brasil. Por exemplo, foi o país que mais horas transmitiu nos JP de 2004

Movimento, Porto Alegre, v. 20, n. 3, p. 989-1015, jul./set. de 2014. 
(168h), seguido pela Espanha (125h) (FIGUEIREDO; GUERRA, 2005). A cobertura midiática brasileira parece ser mais abrangente e diversificada do que a de alguns países. Por exemplo, ela ofereceu mais informações sobre a preparação dos atletas e bastidores das competições durante os JP de 1996 a 2008, do que a portuguesa (FIGUEIREDO; NOVAIS, 2011).

Pode-se também citar a pequena atenção dada pela mídia norte-americana ao esporte paralímpico, que praticamente resumese a 2 ou 3 semanas durante os JP. Ou seja, há alguma divulgação a cada quatro anos, sendo ignorados os demais eventos (BRITTAIN, 2004; COAKLEY, 2008).

\section{Tema 2 - Divulgação das dificuldades do atleta com deficiência e/ou seus feitos esportivos.}

DSC 1 - IC-A: As duas abordagens são importantes - S1; S2; S3; S4; S6; S7; S8; S13; S20; S22

Eu penso que as duas abordagens têm a mesma importância. Não há problema em tratar tanto da superação quanto do resultado. Acho que o esporte paralímpico teria que ser divulgado como uma competição, enfatizar a disputa e aí sim, destacar a superação esportiva.

DSC 2 - IC-B: Divulgar a superação das dificuldades é uma forma de encorajar e valorizar pessoas com deficiência - S1; S3; S8; S22

É bom mostrar a superação da deficiência para as pessoas. Tem muita gente que tem alguma deficiência que fica em casa e muitas vezes não sabe das oportunidades de prática esportiva. Esse discurso de superação ajuda a gente a enfrentar os medos e os nossos próprios limites. Porque tem muita gente que passa a infância todinha escondendo a deficiência e, quando vira atleta, a mostra para todos. Aí descobre que pode ser mais feliz. 
DSC3 - IC-C: Preferência por maior atenção aos feitos esportivos dos atletas - S2; S5; S6; S8; S9; S10; S11; S12; S13; S20; S21; S22; S23

Eu acho a nossa mídia um pouco sensacionalista. A gente quer que isso mude. A gente está jogando e em vez do pessoal falar que a gente está bem preparado, em boa forma física, que teve um treinamento adequado, não. Eles sempre falam: "Olha lá. Eles se superaram. Isso é um exemplo para todo mundo. $\mathrm{O}$ que a gente não faz eles fazem". Eu não concordo muito. Isso é um discurso que me incomoda muito. $\mathrm{O}$ pior sentimento que o ser humano pode ter sobre o outro é o de pena. É muito ruim porque ninguém é melhor nem pior do que ninguém, as pessoas são diferentes. Toda reportagem sobre esporte paralímpico tem aquela música de fundo que remete a superar limites, ultrapassar barreiras. Isso não existe. Eu sou uma pessoa com deficiência. Paciência. A vida pode até ser mais difícil, mas esportivamente sou como qualquer atleta. Eu acho que poderia acabar esse discurso de que a gente é coitado. Não, a gente não é coitadinho. A gente é atleta de alto rendimento.

DSC4 - IC-D: Sensacionalismo sobre as dificuldades causadas pela deficiência não ajuda a divulgar o esporte - S12; S13; S23

A mídia às vezes não mostra algumas coisas porque talvez aquilo não vai vender. Se a mídia divulgasse mais o aspecto esportivo do esporte paralímpico ia ser uma maravilha. É o problema do preconceito: ver a pessoa com deficiência ou como coitadinho, ou como um herói, simplesmente porque ela agora participa de uma competição. Isso é muito negativo e estimula o preconceito. Se nós vamos ser admirados, sejamos como um atleta deve ser admirado, e não porque somos coitadinhos.

Assim como atletas paralímpicos norte-americanos e britânicos (HARDIN; HARDIN, 2004; BERGER, 2008; SILVA; HOWE, 2012), os sujeitos deste trabalho não foram consensuais

Movimento, Porto Alegre, v. 20, n. 3, p. 989-1015, jul./set. de 2014. 
frente aos diferentes enfoques utilizados pela mídia. Destacamse três posicionamentos: preferência por divulgação dos feitos atléticos e incômodo com o foco na superação da deficiência (ICC); percepção otimista quanto à superação da deficiência (IC-B); percepção positiva em relação a um equilíbrio entre as duas formas (IC-A).

Ambas as possibilidades acontecem na mídia paralímpica (MARQUES et al., 2013), porém, a perspectiva da IC-B é mais recorrente e tradicional (BERGER, 2008; HOWE, 2008; FARIA; CARVALHO, 2010; FIGUEIREDO; NOVAIS, 2011; SILVA; HOWE, 2012; VON SIKORSKI; SCHIERL, 2012).

A literatura (HARDIN; HARDIN, 2004; BERGER, 2008; SILVA; HOWE, 2012) denomina como supercrip a tendência sensacionalista de divulgação do atleta com deficiência como um herói que, mesmo com as desvantagens que lhe são impostas, supera-as e consegue feitos extraordinários. Essa percepção implica em um processo estereotipante que requer uma luta pessoal contra as limitações, para superá-las e alcançar o sucesso (SILVA; HOWE, 2012).

Os sujeitos entrevistados posicionaram-se em maioria quanto à preferência por destaques de seus feitos atléticos e incômodo com o discurso supercrip (IC-C). Tal evidência reforça o posicionamento político-social dos atletas em relação à valorização do modelo social de deficiência, pautado na valorização das potencialidades das PCD e suas diferentes possibilidades de atuação na sociedade. Percebe-se que a maioria dos sujeitos entrevistados toma partido de uma postura ligada à valorização de sua atuação e papel social de atleta, muito mais vinculada aos feitos esportivos do que à condição de deficiência. Fica evidente o discurso de protesto em relação a uma forma de difusão de ideias pautada no modelo médico de deficiência (supercrip).

Alguns atletas estrangeiros compartilham desse posicionamento (HARDIN; HARDIN, 2004; BERGER, 2008; PURDUE; HOWE, 2012), até justificando que o supercrip cria 
uma expectativa, por parte da sociedade, ligada a desempenhos esportivos menos importantes do que os atletas olímpicos e expressando certo temor frente a uma possível perda de espaço publicitário com outro tipo de abordagem (HARDIN; HARDIN, 2004).

Percebe-se que o supercrip, embora trate os atletas com deficiência de forma paradoxal (simultaneamente como coitados e heróis), apresenta-se como uma forma de capital simbólico do esporte paralímpico no campo midiático. Em outras palavras, uma identidade dessa forma de esporte que a diferenciaria de outras e, assim, possibilitaria maior divulgação e audiência através de um enfoque sensacionalista. Tal perspectiva encontra respaldo na divulgação dos atletas como o "exótico humano", que gera maior audiência do que seus feitos esportivos (NOVAIS; FIGUEIREDO, 2010) e, dessa forma, garantem "boas notícias" (HOWE, 2008), alimentando a indústria midiática esportiva (SILVA; HOWE, 2012), mas não a legitimação dos atletas paralímpicos como esportistas de elite (BERGER, 2008).

Ao divulgar o discurso supercrip, a mídia explora a compaixão dos espectadores pelos atletas paralímpicos, tratandoos como vítimas (FIGUEIREDO; GUERRA, 2005). O problema é que tal tendência dificulta o surgimento da admiração pelos feitos atléticos, dificultando a formação de ídolos esportivos (NOVAIS; FIGUEIREDO, 2010). Cria-se certa "assepsia moral", ou seja, trata-se o esporte paralímpico de modo puritano, desvinculado de qualquer senso crítico por parte da mídia. Temas controversos, como doping e rendimentos não satisfatórios de atletas, não são destacados, diferenciando do esporte olímpico e criando uma aura de marginalização e desprestígio (HOWE, 2008).

Embora muitos atletas paralímpicos prefiram ser tratados por seus feitos atléticos, alguns aceitam o discurso supercrip para que recebam alguma pequena exposição midiática (HARDIN; HARDIN, 2004; COAKLEY, 2008), visto que a falta de divulgação contribui para inibir o envolvimento de PCD em práticas esportivas

Movimento, Porto Alegre, v. 20, n. 3, p. 989-1015, jul./set. de 2014. 
(BRITTAIN, 2004). Esse posicionamento foi também encontrado entre sujeitos deste trabalho (IC-B). Além de alguns assumirem que tal perspectiva possibilita certo acesso à mídia, outros destacam que o supercrip pode motivar PCD à adesão à prática esportiva. Esse grupo encontra apoio em parte dos atletas entrevistados por Berger (2008) e Hardin e Hardin (2004), que julgam o supercrip como uma forma de mostrar a deficiência de modo positivo, destacando a determinação e o poder de superação das PCD.

Talvez pelos aspectos positivos e negativos (mais destacados) expostos pela literatura, alguns entrevistados deste trabalho aprovam ambos os tipos de abordagens (IC-A). Percebe-se em seus discursos tanto a preocupação com a valorização do esportista com deficiência como um atleta de alto rendimento, quanto também simpatia com a disseminação da perspectiva da superação das dificuldades e barreiras sociais sobre as PCD.

Tanto os sujeitos ligados à IC-A, quanto IC-B, mostramse menos relutantes ao ideal supercrip. Tal perspectiva elucida, principalmente, dois tipos de posicionamento político-social: a) o primeiro ligado à divulgação do esporte para $\mathrm{PCD}$, independente dos meios utilizados para isso; b) o segundo ligado a uma postura menos crítica à perspectiva médica de deficiência e mais vinculada à associação do esporte como ferramenta de estímulo às PCD para buscarem meios de participarem de forma mais atuante na sociedade.

Em contrapartida, os sujeitos que percebem o supercrip como um discurso que não contribui para a divulgação do esporte (IC-D), assumem um posicionamento próximo da IC-C e encontram certo apoio na literatura (BRITTAIN, 2004). Para alguns autores, essa forma de abordagem baseia-se no paradigma médico de deficiência e fortalece estereótipos de dependência e ineficiência, contribuindo para a disseminação da discriminação e preconceito (HARDIN; HARDIN, 2004; HOWE, 2008; PEREIRA; MONTEIRO; PEREIRA, 2011; FIGUEIREDO; NOVAIS, 2011; SILVA; HOWE, 2012).

Movimento, Porto Alegre, v. 20, n. 3, p. 989-1015, jul./set. de 2014. 
Por outro lado, ao destacar a ênfase nos feitos esportivos e tratar atletas olímpicos e paralímpicos sob a mesma perspectiva, a mídia pode ajudar a fortalecer a inclusão social e diminuir o preconceito (NOVAIS; FIGUEIREDO, 2010; VON SIVORSKI; SCHIERL, 2012). Assim, a deficiência daria lugar à eficiência e a limitação à potencialidade (MORATO et al., 2011).

Tema 3 - Comparações entre esporte olímpico e paralímpico na mídia.

DSC 1 - IC-A: Há maior divulgação do esporte olímpico - S3; S9; S22

A divulgação do esporte olímpico é ampla e sempre acontece, mas você nunca tem notícia sobre o paralímpico, só canal fechado transmite, com menor abrangência e quantidade de eventos. Por exemplo, quando uma seleção paralímpica é convocada, não há divulgação, ou quando o Daniel Dias ganhou seis medalhas de ouro, você não viu na TV aberta ele nadando nenhuma vez. Já na época das Olimpíadas, as emissoras interrompem a programação normal para transmitir uma prova do César Cielo.

DSC 2 - IC-B: É preciso cautela com a comparação entre os esportes olímpico e paralímpico em relação ao quadro de medalhas $-\mathrm{S} 13$

Quando a gente observa, por exemplo, o quadro de medalhas das Paralimpíadas, comparando com as Olimpíadas, a gente sempre percebe que as Paralimpíadas, estatisticamente, trazem melhores resultados. Mas eu acho que isso é algo que a gente tem que ver com cautela. Por exemplo, você tem mais de 10 vezes o número de medalhas no atletismo paralímpico do que no olímpico. E mesmo observando o ranking, eu acho que é um pouco temerário, porque tem que ver: a quantidade de países que está participando é a mesma?

DSC3 - IC-C: O esporte paralímpico do Brasil é mais produtivo do que o olímpico - S22; S23

Movimento, Porto Alegre, v. 20, n. 3, p. 989-1015, jul./set. de 2014. 
Porque se você for comparar, nós somos muito melhores que os olímpicos. A gente é $7^{\circ}$ colocado no quadro geral da paralimpíada, o olímpico ficou em qual lugar? O que eu comparo é o quadro de medalhas. Eu estou em $7^{\circ}$. E o olímpico está onde? Então na minha cabeça, o paralímpico é mais bem sucedido.

A comparação entre os universos olímpico e paralímpico é tema latente tanto no campo jornalístico quanto no acadêmico. Nesse cenário, o movimento paralímpico coloca-se como herdeiro do olímpico, principalmente quanto à organização, divulgação e comercialização de símbolos e objetos (MARQUES et al., 2009). Tal tema mostrou-se presente no discurso de alguns atletas entrevistados neste estudo. Os sujeitos que compararam as coberturas midiáticas olímpica e paralímpica destacaram a predominância da primeira sobre a segunda (IC-A).

É possível encontrar relatos na literatura congruentes com tal posicionamento. Das notícias brasileiras e portuguesas referentes aos JP e Jogos Olímpicos (JO) de 2008, 27\% referiram-se ao primeiro e $73 \%$ ao segundo (NOVAIS; FIGUEIREDO, 2010). Outros autores justificam essa diferença pela baixa valorização do movimento paralímpico no campo midiático (SCHANTZ; GILBERT, 2001; BRITTAIN, 2004; FIGUEIREDO; GUERRA, 2005), ilustrada pela menor importância dada por autoridades políticas aos eventos paralímpicos em relação aos olímpicos, ilustrando sua secundarização (GONÇALVES; ALBINO; VAZ, 2009).

Além disso, Novais e Figueiredo (2010) apontam que as notícias olímpicas são mais carregadas de dramatização e detalhes a respeito dos desempenhos dos atletas e dos bastidores das disputas, enquanto que as paralímpicas apenas resumem-se à descrição de resultados. Isso se coloca como um problema, visto que o mercado esportivo requer uma contribuição por parte da mídia para a cobertura e notícias que extrapolem o momento das competições, possibilitando maior vínculo entre consumidores e atletas (COAKLEY, 2008). 
Percebeu-se certa discordância nos discursos de alguns atletas, principalmente em relação à comparação de desempenho esportivo brasileiro olímpico e paralímpico (IC-B; IC-C). S22 e S23 reivindicaram maior espaço midiático a partir da justificativa do melhor rendimento de atletas paralímpicos brasileiros em relação aos olímpicos. Por outro lado, S13 sugere cautela nessa comparação, devido às diferenças nos critérios de premiação e quantificação do quadro de medalhas entre os JO e JP. Este atleta encontra respaldo na literatura (HOWE; JONES, 2006; MARQUES et al., 2009).

A falta de consenso sobre o tema demonstra duas perspectivas diferentes de procura por maior valorização do capital simbólico do esporte paralímpico no campo esportivo: a) a primeira por uma via de maior destaque à quantidade de conquistas paralímpicas; b) a segunda pela valorização do movimento paralímpico como um fenômeno importante por si só, independente de comparação com o olímpico. Nota-se nesses discursos uma tendência similar de busca por melhoria do potencial midiático e comercial do movimento paralímpico, algo que, de acordo com os dados encontrados neste trabalho, parece ser característico do habitus dos atletas entrevistados.

De todo modo, em termos absolutos, Novais e Figueiredo (2010) apontam que o número de notícias referentes ao esporte olímpico e paralímpico no Brasil e em Portugal não é proporcional às medalhas conquistadas por atletas de ambos os países. Tais dados refletem uma maior exposição dos atletas olímpicos, independentemente de qualquer comparação meritocrática quanto ao número de medalhas conquistadas, o que corrobora IC-A.

\section{Considerações finaIS}

Existe uma disputa histórica em relação à inclusão de PCD em diversos setores da sociedade (DUARTE; SANTOS, 2003). Tal processo passa desde a conservadora adoção de uma perspectiva médica até uma inovadora maior valorização do modelo social de deficiência a partir do final do século XX. Alguns agentes atuam nesse

Movimento, Porto Alegre, v. 20, n. 3, p. 989-1015, jul./set. de 2014. 
processo, principalmente através da mídia, como disseminadores de ideais transformadores. Entre eles estão os atletas.

A mídia tem o poder de influenciar a forma como as pessoas se posicionam frente ao espaço social, inclusive sobre questões relativas a PCD (COAKLEY, 2008; PEREIRA; MONTEIRO; PEREIRA, 2011). Os atletas entrevistados neste trabalho mostram que a mídia esportiva é um fator relevante sobre sua prática e expectativa de construção de uma carreira, visto que influencia suas possibilidades de reconhecimento social e ganhos financeiros.

Seus discursos sugerem que existe um habitus próprio de atletas paralímpicos, no sentido de simbolizarem a disseminação de uma perspectiva que destaque uma participação eficiente de PCD na sociedade. A fala ligada à maior valorização dos feitos atléticos, associada ao incômodo com o discurso supercrip, reivindicação por maior espaço na mídia e consequentes maiores possibilidades de ganhos sociais e financeiros, destaca um habitus ligado a uma forma de prática esportiva com agentes carregados de criticidade e de busca por atuação social transformadora.

Discursos como os apresentados neste trabalho podem contribuir para a promoção do modelo social de deficiência, no sentido de mudar a forma como a sociedade percebe e inclui as PCD em seus diferentes espaços. Nesse sentido, o método de pesquisa utilizado proporcionou o destaque dos pontos de vista dos atletas entrevistados, de modo a agrupar consensos e elucidar algumas divergências de opiniões entre os sujeitos.

O fato de não haver entre os entrevistados um consenso sobre a preferência por certos tipos de divulgação demonstra que esse é um tema em ebulição e que demanda maiores estudos, visto que as diferentes perspectivas podem resultar em diversas consequências para as PCD, principalmente quanto à inclusão social como cidadãos plenos.

Acredita-se que os resultados oriundos desta pesquisa possam oferecer subsídios para uma discussão de um habitus próprio da 
A abordagem midiática sobre o esporte ...

abordagem midiática sobre o esporte paralímpico. Porém, por tratar-se de uma análise sobre as opiniões de um grupo específico, tais considerações remetem-se à realidade própria desse campo social, com seus capitais em disputa, habitus de diferentes agentes e relativa autonomia dentro do movimento paralímpico. 
Media approach to Paralympic sports: Brazilian athletes' standpoint

Abstract: Paralympic sports are in a process of economic and social affirmation, and the media are the main tool to disseminate their ideas and products. Based on concepts of Pierre Bourdieu's field theory, the aim of this study was to investigate the standpoint of Brazilian athletes on contents, media and scope to publicize Paralympic sports, in order to propose reflections about their expectations and perceptions. Supported by data from semistructured interviews with 23 Brazilian Paralympic athletes and discourse analysis using the method of Discourse of the Collective Subject, the main results were: Paralympic publicizing is still low, but it is growing; athletes are divided between those who prefer to publicize sporting achievements and those who favor the idea of overcoming disability.

Keywords: Sports. Audio-visual Media. Disabled persons. Sociology.

El enfoque mediático en el deporte paralimpico: punto de vista de los atletas brasileños

Resumen: El deporte paralímpico se encuentra en proceso de afirmación económica y social, y tiene en los medios de comunicación la principal herramienta para difundir sus ideas y productos. Basado en conceptos de la teoría de los Campos de Bourdieu, el objetivo de este estudio es investigar el punto de vista de los atletas brasileños en cuanto al contenido, los medios y la difusión de los medios de comunicación sobre el deporte paralímpico, con el fin de ofrecer reflexiones sobre sus expectativas y percepciones. A partir de entrevistas semiestructuradas con 23 atletas paralímpicos brasileños y de análisis del discurso basado en el método Discurso del Sujeto Colectivo, presenta como principales resultados: la divulgación paralímpica es aún pequeña, pero creciente; hay una cierta división entre los atletas que prefieren la divulgación de los logros deportivos y la idea de la superación de la discapacidad. Palabras clave: Deportes. Medios audiovisuales. Personas con discapacidad. Sociología. 


\section{REFERÊNCIAS}

BAILEY, S. Athlete first: a history of the paralympic movement. West Sussex: John Wiley, 2008.

BERGER, R. J. Disability and the dedicated wheelchair athlete: beyond the "supercrip" critique. Journal of contemporary ethnography, Feyeteville, v.37, n.6, p. 647-678, 2008.

BOURDIEU, Pierre. Questões de sociologia. Rio de Janeiro: Marco Zero, 1983.

BOURDIEU, Pierre. Coisas ditas. São Paulo: Brasiliense, 1990.

BOURDIEU, Pierre. O poder simbólico. Rio de Janeiro: Bertrand Brasil, 1989.

BOURDIEU, Pierre. Sobre a televisão. Rio de Janeiro: Jorge Zahar, 1997.

BRITTAIN, I. Perception of disability and their impact upon involvement in sport for people with disabilities at all levels. Journal of sport and social issues, Boston v.28, n.4, p.429-452, 2004.

COAKLEY, J. Sports in society: issues and controversies. 10th ed. New York: McGraw-Hill, 2008.

COSTA, A. M. da; WINCKLER, C. A Educação Física e o esporte Paralímpico. In: MELLO, M. T. de; WINCKLER, C. (Org.) Esporte Paralímpico. São Paulo: Atheneu, 2012.

DUARTE, E.; SANTOS, T. P. dos. Adaptação e inclusão. In: DUARTE, E.; LIMA, S. M. T. Atividade Física para pessoas com necessidades especiais: experiências e intervenções pedagógicas. Rio de Janeiro: Guanabara Koogan, 2003. p. 93-99.

FARIA, M. D. de; CARVALHO, J. L. F. Uma análise semiótica do potencial mercadológico da imagem de atletas paraolímpicos. Revista Gestão e Sociedade, Belo Horizonte, v.4, n. 9, p. 657-686, 2010.

FIGUEIREDO, T. H.; GUERRA, M. D. Olimpíadas e Paraolimpíadas: uma correlação com a mídia. In: CONGRESSO BRASILEIRO DE CIÊNCIAS DA COMUNICAÇÃO, 2005. Anais eletrônicos... 2005. Disponível em: < http://www.portcom.intercom.org. br/pdfs/90923980742584942862936767243914154873.pdf>. Acesso em: 01 jul 2013

FIGUEIREDO, T. H.; NOVAIS, R. A. Atletas com deficiências na mídia: a cobertura noticiosa dos jogos Paraolímpicos de Atlanta a Pequim nas imprensas portuguesa e brasileira. In: Anais eletrônicos..., São Paulo: USP, 2011. Disponível em < http:// confibercom.org/anais2011/pdf/354.pdf>. Acesso em: 2 jul 2013.

GONÇALVES, G. C.; ALBINO, B. S.; VAZ, AL. F. O herói esportivo diferente: aspectos do discurso em mídia impressa sobre o Parapan-americano 2007. In: PIRES, G. L. (Org.) Observando o pan Rio/2007 na mídia. Florianópolis: Tribo da Ilha, 2009. p. 149-167.

Movimento, Porto Alegre, v. 20, n. 3, p. 989-1015, jul./set. de 2014. 
HARDIN, M. M.; HARDIN, B. The "supercrip" in sport media: wheelchair athletes discuss hegemony's disabled hero. Sociology of sport online, Wellington v.7, n.1, p.1-14, 2004.

HOWE, P. Sport, professionalism and pain: ethnographies os injkury and risk. New York: Routledge, 2004.

HOWE, P. D. From inside the newsroom: paralimpyc media and the "production" of elite disability. International Review for the Sociology of Sport, Los Angeles, v.43, n.2, p.135-150, 2008.

Sport, professionalism and pain: ethnographies of injury and risk. New York: Routledge, 2004.

HOWE, P. D.; JONES, C. Classification of disabled athletes: (dis) empowering the paralympic practice community. Adapted Phisycal Activity Quaterly, Los Angeles , v.23, p. 29-46, 2006.

LEFÈVRE, F.; LEFÈVRE, A.M.C. O discurso do sujeito coletivo: um novo enfoque em pesquisa qualitativa (desdobramentos). 2. ed. Caxias do Sul: EDUCS, 2005.

LEFÈVRE, F.; LEFÈVRE, A.M.C.. Pesquisa de representação social: um enfoque qualiquantitativo: a metodologia do Discurso do Sujeito Coletivo. 2. ed. Brasília: Liber Livro, 2012.

MARQUES, R. F. R. et al. Mídia e o movimento paraolímpico no Brasil: relações sob o ponto de vista de dirigentes do Comitê Paralímpico Brasileiro. Revista Brasileira de Educação Física e Esporte, São Paulo, v.27, n.4, p.583-596, 2013.

MARQUES, R. F. R. et al. Esporte olímpico e paraolímpico: coincidências, divergências e especificidades numa perspectiva contemporânea. Revista Brasileira de Educação Física e Esporte, São Paulo, v.23, n.4, p.365-377, 2009.

MARQUES, R. F. R.; GUTIERREZ, G. L. O esporte paraolímpico no Brasil: profissionalismo, administração e classificação de atletas. 1 ed., São Paulo: Phorte, 2014.

MARQUES, R. F. R.; GUTIERREZ, G. L . Contribuições teóricas da obra de Pierre Bourdieu à educação nutricional. In: MENDES, R. T.; VILARTA, R.; GUTIERREZ, G. L. (oOrgs.). Qualidade de vida e cultura alimentar. Campinas: IPES, 2009. p. 97-106.

MARQUES, R. F. R.; GUTIERREZ, G. L.; MONTAGNER, P. C. Novas configurações socioeconômicas do esporte contemporâneo. Revista da Educação Física/ UEM, Maringá, v.20, n.4, p.637-648, 2009.

MASSA, M; UEZU, R; BÖHME, M.T.S. Judocas olímpicos brasileiros: fatores de apoio psicossocial para o desenvolvimento do talento esportivo. Revista Brasileira de Educação Física e Esporte, São Paulo, v. 24, n. 4, p. 471-481, 2010.

MINAYO, M. C. de S. O desafio do conhecimento. Pesquisa qualitativa em saúde.

Movimento, Porto Alegre, v. 20, n. 3, p. 989-1015, jul./set. de 2014. 
A abordagem midiática sobre o esporte ...

9. ed. São Paulo: Hucitec, 2006.

MORATO, M. P. et al. A mediação cultural no futebol para cegos. Movimento, Porto Alegre, , v.17, n.4, p.45-63, 2011.

MUNSTER, M. de A. V. et al. Goalball: uma proposta inclusiva. In: ALMEIDA, J. J. G. et al. (Org.) Goalball: invertendo o jogo da inclusão. Campinas: Autores Associados, 2008. p. 9-15.

NOVAIS, R. A.; FIGUEIREDO, T.H. A visão bipolar do pódio: olímpicos versus paraolímpicos na mídia on-line de Brasil e de Portugal. Logos 33, - Rio de Janeiro,v.17, n.2, p. 78-89, 2010.

PEREIRA, O.; MONTEIRO, I; PEREIRA, A. L. A visibilidade da deficiência: - uma revisão sobre as representações sociais das pessoas com deficiência e atletas paraolímpicos nos media impressos. Sociologia, Porto Alegre, v.22, n.2, p.119$217,2011$.

PURDUE, D. E. J.; HOWE, P. D. See the sport, not the disability: exploing the Paralympic paradox. Qualitative research in sport, exercise and health, Loughborough, v.4, n.2, p.189-205, 2012.

SCHANTZ, O. J.; GILBERT, K. An ideal misconstrued: newspaper coverage of the Atlanta Paralympic games in France and Germany. Sociology of sport journal, Champaign, v.18, p.69-94, 2001.

SILVA, C. F.; HOWE, P. D. The (in)validity of supercrip representation of Paralympic athletes. Journal of sport and social issues, Boston, v.36, n.2, p.174-194, 2012.

VON SIKORSKI, C.; SCHIERL, T. Effects of news frames on recipients'information processing in disability sport communications. Journal of media psycology , Colonia, v. 24, n.3, p.113-123, 2012.

Agências de fomento: Núcleo Interdisciplinar de Pesquisas sobre Futebol e Modalidades Lúdicas (USP) e Comitê Paralímpico Brasileiro

Endereço para correspondência

Renato Francisco Rodrigues Marques

Escola de Educação Física e Esporte de Ribeirão Preto - Universidade de São Paulo.

Avenida Bandeirantes, 3900, Monte Alegre, Ribeirão Preto/SP

CEP 14040-907.

Recebido em: 07.10.2013

Aprovado em: 01.05.2014

Movimento, Porto Alegre, v. 20, n. 3, p. 989-1015, jul./set. de 2014. 